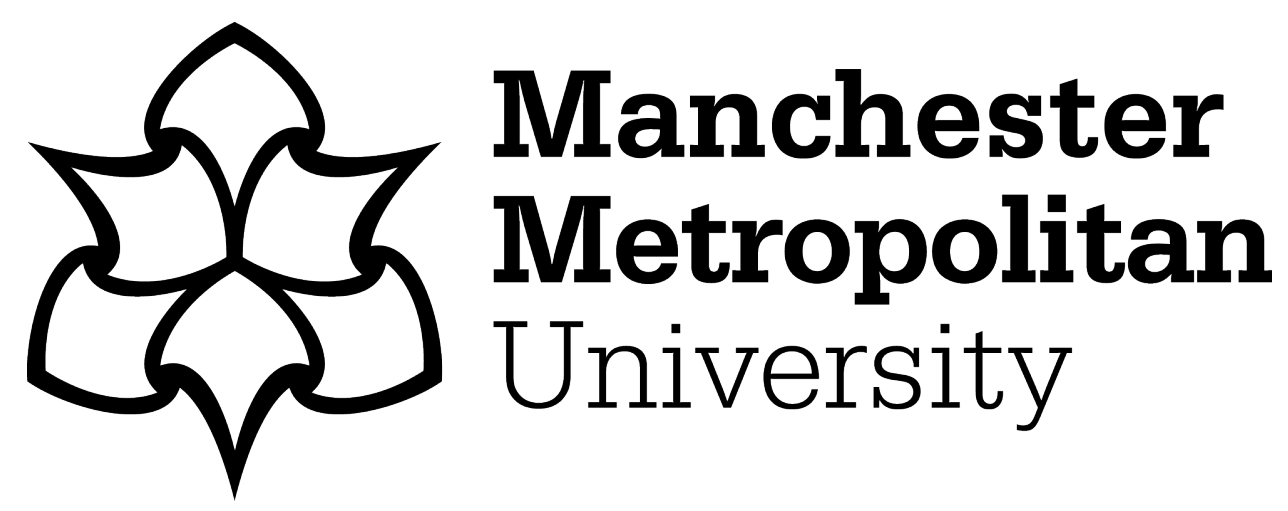

Dou, P, Xue, MA, Zheng, J, Zhang, C and Qian, L ORCID logoORCID: https://orcid.org/0000-0002-9716-2342 (2020) Numerical and experimental study of tuned liquid damper effects on suppressing nonlinear vibration of elastic supporting structural platform. Nonlinear Dynamics, 99 (4). pp. 26752691. ISSN 0924-090X

Downloaded from: https://e-space.mmu.ac.uk/624951/

Version: Accepted Version

Publisher: Springer

DOI: https://doi.org/10.1007/s11071-019-05447-y

Please cite the published version 


\section{Nonlinear Dynamics}

\section{Numerical and experimental study of tuned liquid damper effects on suppressing nonlinear vibration of elastic supporting structural platform

\author{
--Manuscript Draft--
}

\begin{tabular}{|c|c|}
\hline Manuscript Number: & NODY-D-19-00982 \\
\hline Full Title: & $\begin{array}{l}\text { Numerical and experimental study of tuned liquid damper effects on suppressing } \\
\text { nonlinear vibration of elastic supporting structural platform }\end{array}$ \\
\hline Article Type: & Original Research \\
\hline Keywords: & $\begin{array}{l}\text { tuned liquid damper; supporting structural platform; two-way coupling model; physical } \\
\text { model experiment; nonlinear vibration damping }\end{array}$ \\
\hline Abstract: & $\begin{array}{l}\text { A liquid storage container installed on the top of a fixed offshore platform is used as a } \\
\text { Tuned Liquid Damper (TLD) to suppress structural vibration through sloshing motion } \\
\text { and viscous energy dissipation. To further optimize TLD capability on suppressing } \\
\text { vibration and accurately predict nonlinear coupled processes between TLD and } \\
\text { offshore platform, a two-way coupling numerical model was developed to investigate } \\
\text { the nonlinear vibration of TLD and elastic Supporting Structural Platform (SSP). } \\
\text { Meanwhile, laboratory experiments of TLD interaction with the SSP were also } \\
\text { conducted on a six degree of freedom motion simulator to validate the developed } \\
\text { model. The bottom plate of the SSP was fixed to the motion simulator and subjected to } \\
\text { sinusoidal excitation in the horizontal direction. The natural frequency of bare SSP was } \\
\text { obtained firstly by shaking table tests at a wide range of external excitation frequencies } \\
\text { and finite element modal analysis. The developed numerical model was validated by } \\
\text { using the present experimental data in terms of both the roof plate displacements of } \\
\text { the SSP and the free surface elevation and waveforms in TLD. Effects of TLD in } \\
\text { suppressing the nonlinear vibration of the elastic SSP were further investigated } \\
\text { numerically by varying the mass and frequency ratio of TLD to the SSP. Wavelet } \\
\text { transform was used to analyze the nonlinear interaction and energy distribution } \\
\text { characteristics of the sloshing wave in TLD. It was shown that the peak displacement } \\
\text { response of the roof plate had been significantly reduced and at the same time a } \\
\text { frequency shift occurred after TLD installed on the SSP. In addition, the sudden } \\
\text { excitation breaks the balance of energy absorption and production in fluids resulting in } \\
\text { larger wave height. Finally, a mass ratio of } 2 \% \text { and a frequency ratio of } 1.0 \text { were found } \\
\text { to be optimal by considering the frequency shift and energy dissipation. }\end{array}$ \\
\hline
\end{tabular}




\title{
Numerical and experimental study of tuned liquid damper effects on suppressing nonlinear vibration of elastic supporting structural platform
}

\author{
Peng Dou $\cdot$ Mi-An Xue $\cdot$ Jinhai Zheng $\cdot$ Chi Zhang $\cdot$ Ling Qian
}

\begin{abstract}
A liquid storage container installed on the top of a fixed offshore platform is used as a Tuned Liquid Damper (TLD) to suppress structural vibration through sloshing motion and viscous energy dissipation. To further optimize TLD capability on suppressing vibration and accurately predict nonlinear coupled processes between TLD and offshore platform, a two-way coupling numerical model was developed to investigate the nonlinear vibration of TLD and elastic Supporting Structural Platform (SSP). Meanwhile, laboratory experiments of TLD interaction with the SSP were also conducted on a six degree of freedom motion simulator to validate the developed model. The bottom plate of the SSP was fixed to the motion simulator and subjected to sinusoidal excitation in the horizontal direction. The natural frequency of bare SSP was obtained firstly by shaking table tests at a wide range of external excitation frequencies and finite element modal analysis. The developed numerical model was validated by using the present experimental data in terms of both the roof plate displacements of the SSP and the free surface elevation and waveforms in TLD. Effects of TLD in suppressing the nonlinear vibration of the elastic SSP were further investigated numerically by varying the mass and frequency ratio of TLD to the SSP. Wavelet transform was used to analyze the nonlinear interaction and energy distribution characteristics of the sloshing wave in TLD. It was shown that the peak displacement response of the roof plate had been significantly reduced and at the same time a frequency shift occurred after TLD installed on the SSP. In addition, the sudden excitation breaks the balance of energy absorption and production in fluids resulting in larger wave height. Finally, a mass ratio of $2 \%$ and a frequency ratio of 1.0 were found to be optimal by considering the frequency shift and energy dissipation.
\end{abstract}

Key words tuned liquid damper; supporting structural platform; two-way coupling model; physical model experiment; nonlinear vibration damping

P. Dou · M.-A. Xue (Corresponding author) · J.H. Zheng (Corresponding author) · C. Zhang · L. Qian

State Key Laboratory of Hydrology-Water Resources and Hydraulic Engineering, College of Harbour Coastal and Offshore Engineering, Hohai University, Nanjing 210024, China

P. Dou (e-mail: doup@hhu.edu.cn)

M.-A. Xue (e-mail: mi-anxue@163.com)

J.H. Zheng (e-mail: jhzheng@hhu.edu.cn)

C. Zhang (e-mail: zhangchi@hhu.edu.cn)

L. Qian (e-mail: L.Qian@mmu.ac.uk) 


\section{Introduction}

As a passive energy dissipation device, the Tuned Liquid Damper (TLD) has found an increasingly wide utilization in reducing the dynamic response of elastic Supporting Structural Platform (SSP) under external excitations, especially for the low-frequency vibrations close to the first mode, and therefore an improved structural safety [1,2]. Different from the active or semi-active dampers, passive devices such as TLD have the advantages of relatively lower maintenance requirements, easier installation and zero external energy input. As a consequence, TLDs have attracted much attention from the researchers working on vibrations damping of the slender buildings [3], offshore structures e.g. SSPs [4] and so on.

The liquid with free surface in the tank contributes to the internal damping through induced sloshing which will generate a hydrodynamic force in the opposite direction to the vibration [5]. Generally, the vibrational damages mainly arise from low-frequency resonance and tuning the natural frequency of liquid to that of the structure is important for optimizing the design of SSPs [6-7]. With the increase of oscillation frequency and amplitude, three-dimensional (3D) effects will result in nonlinear behavior of elastic structures and sloshing waves that simplified analytical models cannot predict accurately. Therefore, an accurate description of the free surface flow behavior is needed to understand the sloshing problems. To this end, an empirical parameterization of wave front slope angle was proposed in [8] in order to predict both the first and second breakpoints for regular waves breaking over sloping and barred beaches, and the wave-wave nonlinear interactions using the wavelet-based bicoherence was studied experimentally in [9].

Liquid boundary layer friction, wave breaking and free surface deformation due to sloshing in the tank are the main nonlinear mechanisms of the TLD to reduce the responses of the structure [10]. The change of the sloshing liquid frequency resulting from the nonlinear phenomenon and the shear force between TLD and structure could also be affected by wave motions. To accurately predict the sloshing wave interaction with structures, a 3D turbulent numerical model was developed to investigate the effects of different baffles on reducing violent liquid sloshing wave by using the virtual boundary force (VBF) method and volume of fluid (VOF) method [11-12]. Moreover, a liquid sloshing test rig driven by a wave-maker to study liquid sloshing in a rectangular tank with perforated baffles was used in [13-14]. The linear and nonlinear models for predicting the damper performance were compared in [15], and effectiveness of vibration suppression systems with tuned mass immerged in the sloshing liquid was shown in [16].

In [17], the pitch motion mitigation of floating substructures using a multilayer TLD was proposed. Similarly, multi-TLD blocks were employed to maximize the damping effects in [18]. However, those work did not focus on the relationship between motion phase and energy conversion, and furthermore, the control device used in the same tanks would limit the frequency of vibration reduction [19].

To further explore the suppressing mechanism of TLD for coupled TLD-SSP system with external excitations, several experimental and numerical investigations have been carried out [20-22]. In addition, a real-time hybrid testing method has been developed to evaluate the acceleration of the model under dynamically excited motions [23]. An experimental study which considered dynamic loads of different directions was performed on a prototype structure, and the results for different damping ratios and vibration amplitudes of different excitation modes were presented [24]. A new type of TLD with triangle bars installed at the bottom of container for 
controlling the structural oscillation was proposed in [25], in which an enhanced damping ratio by 40-70\% was observed. A conventional TLD with addition of a floating roof was presented in [26], which reveals that the appearance of floating roof can suppresse wave breaking and this in turn will make the numerical modelling much simpler.

Even though substantial progress has been made in numerical methods for modelling fluid-structure interaction (FSI), the computational costs are still too high for them to be applied for the simulation of the complex coupled systems and high-fidelity 3D FSI simulations fully validated by the experiments are still rare. Instead of one-way FSI simulations [27], a two-way coupled Reynolds-Averaged Navier-Stokes (RANS) method was developed to simulate the pipe-in-pipe concept to reduce vortex-induced vibrations by a finite element model [28]. Low-fidelity and high-fide $\stackrel{\cdots}{m}$ aeroelastic results based on a coupled extended blade-element momentum model and CFL- SD coupled solver was compared in [29]. An analytical model was compared with the Finite Volume Method-Finite Element Method (FVM-FEM) through applying FVM and FEM to calculate fluid and solid domains respectively [30], which was later applied to investigate the damping performance of TLD with real-time hybrid simulation and verified by the numerical method [31].

In order to simulate the motions of the internal free surfaces, smoothed particle hydrodynamics (SPH) method, which adopted Lagrangian formulation, has von developed and widely utilized in engineering predictions [32-33]. A verified multi-liquid Mrs program including buoyancy-correction and surface-tension models was applied to consider various nonlinear features [34], such as internal wave breaking and particle detachment. Each mode is characterized by two eigen frequencies by Lagrangian variational approach from the potential formulation of the fluid motion [35].

An effective FSI numerical model based on FVM/FEM was proposed in this study to investigate the interactions between TLD and elastic SSP. Meanwhile, a physical model of the coupled TLD-SSP system was also designed and built. Laboratory experiments were conducted not only to validate the numerical model, but also to observe some important physical phenomena. The proposed 3D numerical model was firstly validated against with the present experimental data by developing a 3D elastic SSP and TLD coupling system. Effects of TLD on suppressing the nonlinear vibration of SSP were investigated by varying TLD/SSP mass ratio and tuned frequency ratio to explore the coupling mechanism between TLD and SSP in terms of energy damping. The optimal values of the mass and frequency ratios for the coupled TLD-SSP system were proposed in order to achieve the minimum vibration of the platform caused by external loads.

The remaining of the paper is organized as follows. The physical model tests are introduced briefly in Sect. 2 and a two-way coupled model for simulating TLD interaction with elastic SSP is presented in Sect. 3. In Sect. 4, the validation of the numerical model is performed by comparing with the results from the laboratory experiments and in Sect. 5, the damping effects under different mass ratios and tuned frequency ratios between TLD and SSP are investigsted. Finally, some important conclusions from the current work are drawn in Sect. 6.

\section{Physical model}

To date, there have been very few experimental studies conducted on TLD-SSP interactions and a physical model of the coupled TLD-SSP system is introduced in the current work. A bottom plate with a dimension of $500 \times 500 \times 5 \mathrm{~mm}$ was fixed to a six degree of freedom (DOF) 
motion simulation platform, also known as hexapod system, by four screws at each corner. As a connection plane, a roof plate with a dimension of $600 \times 600 \times 5 \mathrm{~mm}$ was utilized to link the tank by screws. Four columns with $4.8 \times 50 \times 1000 \mathrm{~mm}$ dimensions were welded to the top and bottom plates, the columns are initially vertical to the ground and the whole model is shown in Fig. 1. For evaluating the effectiveness of TLD in suppressing structure vibration, a perspex rectangular tank with a dimension of $510 \times 150 \times 470 \mathrm{~mm}$ is designed as shown in Fig. 2, which was partially filled by liquid (water) of depth $D$. The schematic view of a single degree-of-freedom structure coupled to a TLD is presented in Fig. 3. Based on the linear wave theory, the first standing wave angular frequency of the water in rectangular tank can be evaluated by the following equation,

$$
\omega_{F}=\sqrt{\frac{\pi g}{L} \tanh \frac{\pi D}{L}}
$$

where $L, D$ and $g$ are the width of the tank, depth of the liquid and the local gravitational acceleration, respectively. Wave gauges were installed at $2 \mathrm{~cm}$ from the side walls of the tank to monitor the free surface elevation. A high resolution laser displacement sensor was also used to record the horizontal vibrational displacement of the roof plate. The angular frequency of the simplified spring-structure system can be calculated by the following formula,

$$
\omega_{S}=\sqrt{\frac{K_{S}}{M_{S}}}
$$

where $K_{\mathrm{s}}$ and $M_{\mathrm{s}}$ are the stiffness and mass of the structure, respectively. Generally, the resonance frequency of the TLD-SSP coupled system is between the natural frequencies of liquid-tank and elastic supporting structural platform.

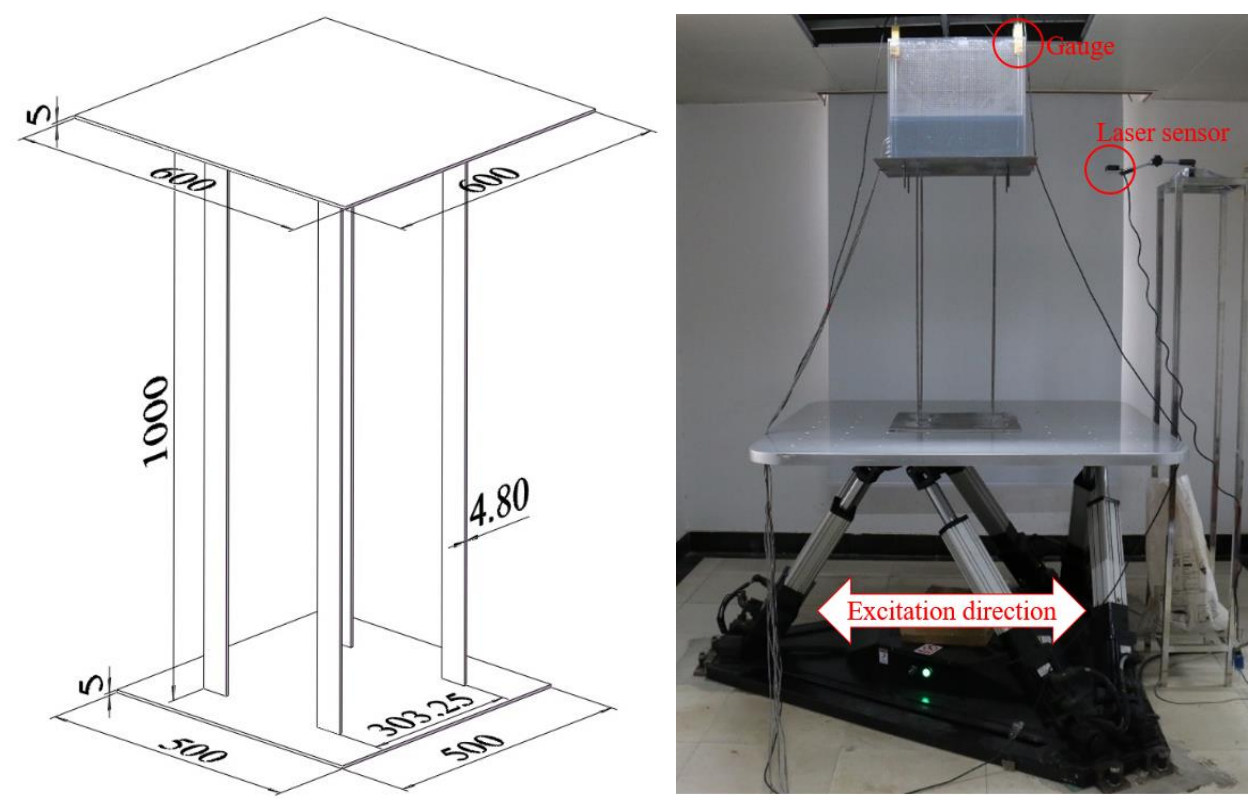

Fig. 1. The SSP test model and the six DOF motion simulator with the coupled TLD-SSP system. 


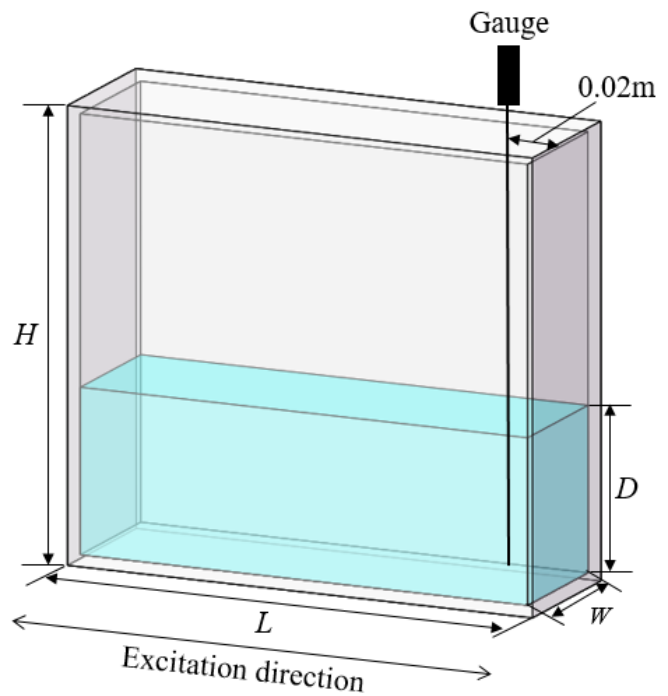

Fig. 2. Sketch of 3D rectangular liquid tank of the TLD.

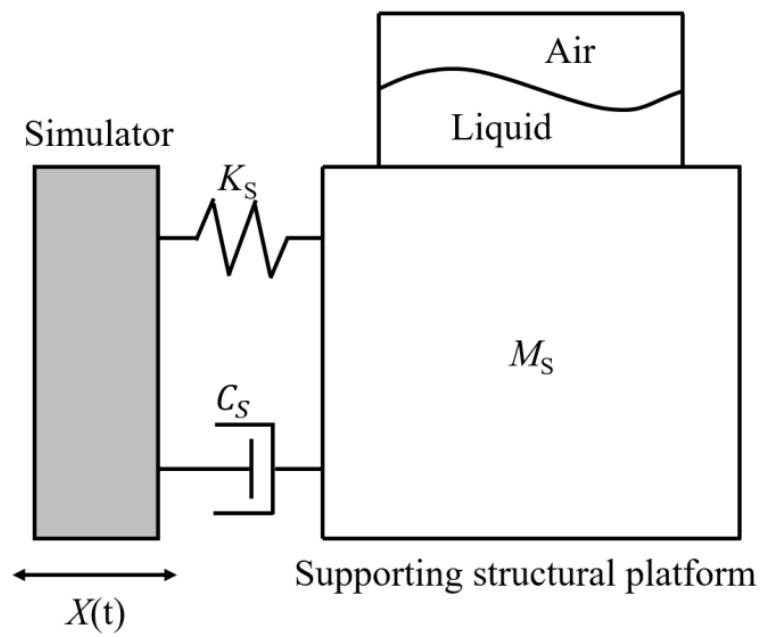

Fig. 3. Equivalent single degree-of-freedom structure coupled to TLD.

\section{Two-way coupling numerical model}

Harmonic sinusoidal motions were generated by the six DOF motion simulator with a horizontal excitation applied on the bottom plate, which lead to the structural vibration of the system. In order to investigate the influence of certain parameters on TLD performance, a coupled numerical model to simulate the TLD-SSP system was constructed. Obviously, the external excitation applied to the bottom plate will cause the oscillation, through supporting structure, of the container located on top of the roof plate. Meanwhile, the liquid will move in the container, and the resulting sloshing force, in turn, will cause the support structure to deform. So, it is a complicated system to simulate as not only the free surface flow inside the container and structural deformation should be solved accurately but also the interaction between them needs to be considered at the same time. Therefore, in this study, an FSI model has been developed based on ANSYS Workbench to perform the transient performance analysis. The model is divided into a fluid field and a corresponding solid field, which are solved by Fluent and Mechanical solver respectively and coupled in a two-way iterative manner.

\subsection{Fluid domain solver}


For incompressible viscous flow with the surface tension between different phases included, the governing equations including conservation of mass and momentum for the fluid domain can be written as:

$$
\begin{aligned}
& \frac{\partial \rho}{\partial t}+\nabla(\rho \boldsymbol{v})=0 \\
& \frac{\partial}{\partial t}(\rho \boldsymbol{v})+\nabla(\rho \boldsymbol{v} \boldsymbol{v})=\nabla \boldsymbol{\tau}+\boldsymbol{F}
\end{aligned}
$$

where $\rho$ is the density; $\boldsymbol{v}$ the fluid velocity vector; $\boldsymbol{F}$ the body force vector; $\boldsymbol{\tau}$ the stress tensor and can be described as

$$
\begin{aligned}
& \boldsymbol{\tau}=(-p+\mu \nabla \cdot \boldsymbol{v}) I+\mathbf{2} \boldsymbol{\mu} \boldsymbol{e} \\
& \boldsymbol{e}=\frac{1}{2}\left(\nabla v+\nabla v^{\mathrm{T}}\right)
\end{aligned}
$$

where $p$ is fluid pressure; $\mu$ is the liquid kinetic viscosity; $\boldsymbol{e}$ is velocity stress tensor. The inhomogeneous free surface model was selected in the current work which allows one phase to enter into another phase. The surface tension $\boldsymbol{F}_{1,2}$ is expressed as

$$
\boldsymbol{F}_{1,2}=\left(-\sigma_{1,2} k_{1,2} \boldsymbol{n}_{1,2}+\nabla_{S} \cdot \sigma_{1,2}\right) \boldsymbol{A}_{1,2}
$$

where $\sigma_{1,2}, k_{1,2}, \boldsymbol{n}_{1,2}$ and $\nabla_{S}$ are the surface tension coefficient, surface curvature, interface unit normal vector pointing from liquid to air and the gradient operator on the interface, respectively.

The computational domain of fluid is discretized and solved by FVM and the unstructured grid was employed to simulate the free surface flow inside the container. Dynamic mesh was adopted to transfer structural displacement, and SIMPLE method was utilized to solve the pressure-velocity coupling. Second-order central-difference scheme was adopted for the convection term, and the VOF method was adopted to track the free surface. In all the cases, the flow turbulence was simulated with Large Eddy Simulation (LES) and the Sub-Grid Scale model (SGS) stress is described as

$$
\tau_{i j}=\rho \overline{u_{\imath} u_{\jmath}}-\overline{u_{\imath}} \bar{u}_{J}
$$

in which, $\bar{u}_{l}$ and $\bar{u}_{J}$ are velocity field component after filtering. Due to the stress in the large eddy simulation governing equation is unknown, the expression of stress must be constructed by the relevant physical quantities. The earliest model was proposed in [36] and improved by many researchers [37-38]. In the study, SGS stress is defined as

$$
\begin{aligned}
& \tau_{i j}=\frac{1}{3} \tau_{k k} \delta_{i j}-2 \mu_{t} \bar{S}_{i j} \\
& \mu_{t}=\rho L_{S}^{2} \sqrt{2 \bar{S}_{i j} \bar{S}_{i j}} \\
& \bar{S}_{i j}=\frac{1}{2}\left(\frac{\partial \bar{u}_{i}}{\partial x_{j}}+\frac{\partial \bar{u}_{u}}{\partial x_{i}}\right) \\
& L_{S}=\min \left(K d, C_{S} V^{1 / 3}\right)
\end{aligned}
$$

where $\mu_{t}$ is the SGS turbulent viscosity; $K$ is the Karman constant; $d$ is the nearest distance from the element to the wall; $V$ is the volume of computing unit; $C_{S}$ the Smagorinsky constant; $L_{S}$ is the mixed length of SGS.

\subsection{Solid domain solver}

The solid domain contains a steel structure and a rectangular tank and relative displacements of tank and roof plate in the tangential and normal directions are constrained. One degree of horizontal sinusoidal excitation was applied to the bottom plate of the solid domain and the 
incremental finite element equilibrium equations used is

$$
\left[M_{S}\right]\{\ddot{q}\}+\left[C_{S}\right]\{\dot{q}\}+\left[K_{S}\right]\{q\}=\{F(t)\}
$$

where $\left[M_{S}\right],\left[C_{S}\right]$ and $\left[K_{S}\right]$ are the constant matrix of mass, damping and stiffness respectively; $\{\ddot{q}\}$ is the cross-flow acceleration vector, $\{\dot{q}\}$ is the cross-flow velocity vector, $\{q\}$ is the cross-flow displacement vector; $\{F(t)\}$ is the applied load vector at time $t$. The material of the structure used in the calculation is 304 stainless steel with a density and Young's modulus of 7930 $\mathrm{kg} / \mathrm{m}^{3}$ and $2 \times 10^{11} \mathrm{~Pa}$, respectively. The tank material was made of plexiglass with a density of $1190 \mathrm{~kg} / \mathrm{m}^{3}$, and considered to be a rigid tank.

\subsection{FSI modeling}

The fluid pressure and structural deformation are transferred on the inner walls of the tank which defined as FSI boundaries. After transient fluid and solid domains are analyzed by CFD and FEM respectively, the system coupling solver will be utilized to transfer data between the two domains at each time step as shown in Fig. 4.

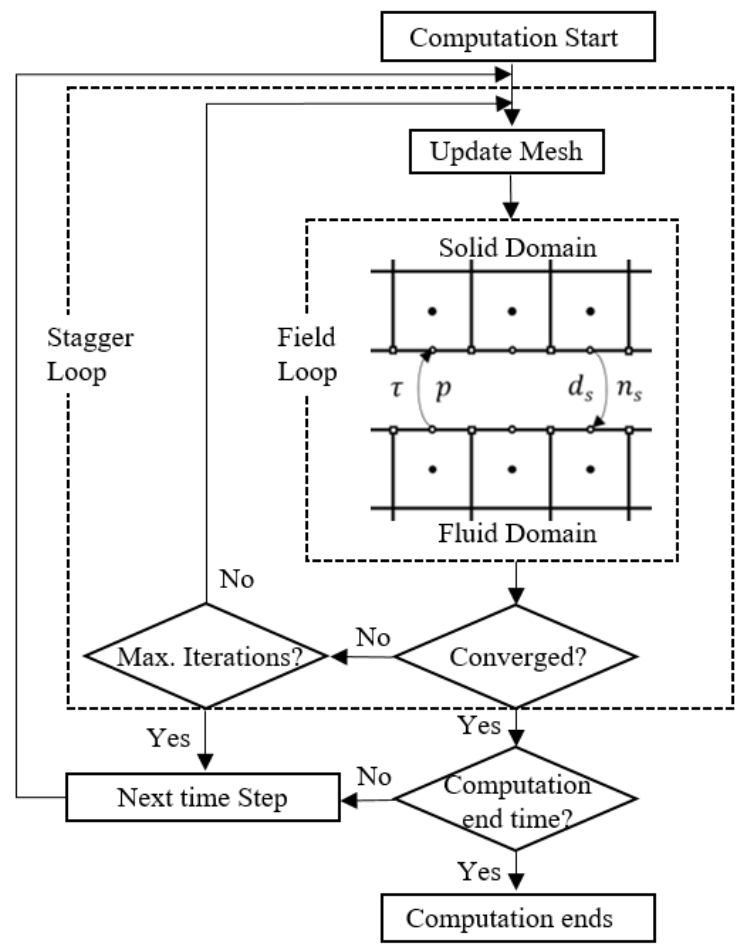

Fig. 4. Diagram of two-way fluid-solid coupling solution.

At the coupling interfaces between the fluid and the solid, the fundamental kinematic equation applied is.

$$
\left\{\begin{aligned}
\tau_{f} n_{f} & =\tau_{s} n_{s} \\
d_{f} & =d_{s}
\end{aligned}\right.
$$

$\tau_{f}$ and $\tau_{s}$ are the stress of the fluid and the solid, respectively. $n_{f}$ and $n_{s}$ are the unit direction vector of the fluid and the solid, respectively. $d_{f}$ and $d_{s}$ are the displacement of the fluid and the solid, respectively.

The interior walls of the tank and the boundaries of the fluid domain were defined as FSI boundaries to transfer the data of loads and deformations, in order to reduce the errors resulted from interpolating exchange on them, the grids on FSI faces were set as the same size. In the coupling solution, the time step was selected as $0.005 \mathrm{~s}$ which is the coincident time both in fluid 
and solid domain. Five coupling interactions with twenty-five max iterations in fluid for each coupling step were utilized for guaranteeing the accuracy of solutions. Only when the fluid field and the solid field converge at the same time step, or reach the maximum number of iterations, the coupling system will proceed to the next step of calculation.

\section{Numerical model validation}

For the validation of solid domain, the constituted FE model of the structure was used for acquiring natural frequencie modal module firstly. In Table 1, the natural frequency of the elastic SSP whether connecteu with TLD are presented numerically and experimentally. Obviously, $\omega_{S}$ decreased as the tank connected on the top plate because of the total mass $M_{\mathrm{S}}$ increased, the modal analysis calculated by FE method matches well with the first resonance frequency by experimental sweep frequency tests. Besides, the first three mode shapes are presented in Fig. 4, as is shown, the first and third resonance mode is horizontal motion along the $\mathrm{x}$-axis and $\mathrm{y}$-axis respectively, in which the colour represents the total deformation. In the study, the second and third resonance is $12.08 \mathrm{~Hz}$ and $17.94 \mathrm{~Hz}$ respectively, so the influence of other vibration modes was neglected.

Table 1 Comparison of the natural frequencies obtained by experiment and FEM.

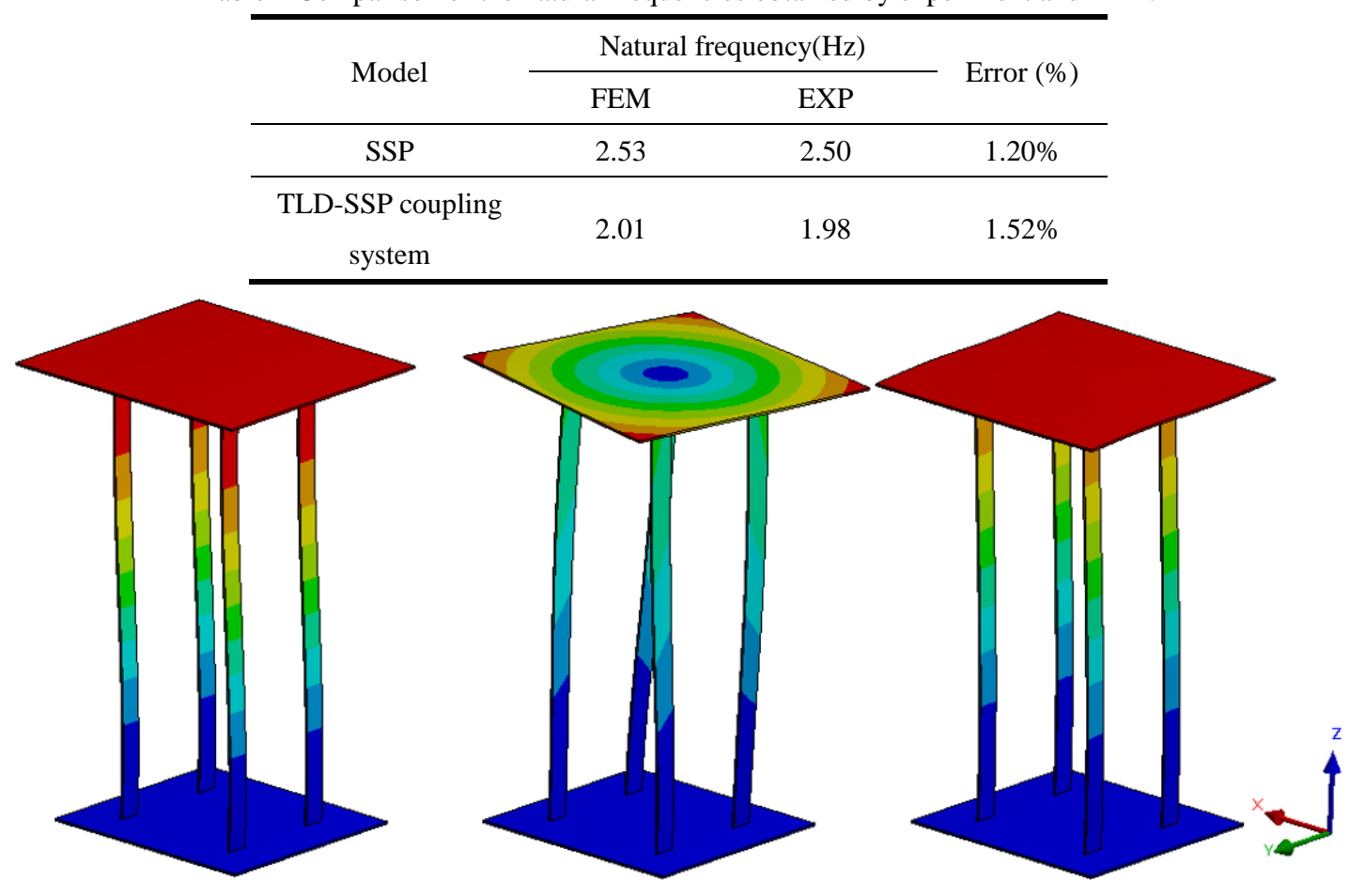

Fig. 4. First three mode shapes $1 \cdots$...ned numerically.

After validating the solid part, as shown in Fig. 1, the physical model of TLD-SSP system was constructed in the Laboratory of Vibration Test and Liquid Sloshing at Hohai University, China, and the level of water in the TLD was $178.5 \mathrm{~mm}$ which is $35 \%$ of the tank length $L$. The maximum and average displacements of the roof versus external excitation frequencies $f_{e}$ ranging from $0.5 \mathrm{~Hz}$ to $2.5 \mathrm{~Hz}$ under horizonal sinusoidal excitation amplitude of $3 \mathrm{~mm}$ are presented in Fig. 6. It can been seen that the natural frequency of TLD-SSP system is located as $1.90 \mathrm{~Hz}$. According to the natural frequency of the bare structure, the resonant frequency of 
TLD-SSP (dash-dotted line) reduced from $2.53 \mathrm{~Hz}$ to $1.90 \mathrm{~Hz}$ indicating the rate of first resonance frequency reduction was $24.9 \%$, and the maximum displacement decreased by $62.45 \%$, compared with bare structure. The shift of first resonance frequency is caused by the increased mass of tank and water and has been reported in previous work [24]. It is noted that, the total mass $M_{\mathrm{s}}$ increased after TLD installation onto the structure and the natural frequency reduced, however, a second peak appears at a low frequency between $0.8 \mathrm{~Hz}$ to $1.1 \mathrm{~Hz}$ which indicates vibration suppressing capability was negatively affected. The reason for this is that when the external excitation frequency approaches to that of liquid, it strengthens the sloshing waves in the tank and therefore increases the shear force acting on the structure.

As can be seen in Fig. 6, spectral peak frequency corresponding to the sub-peak amplitude value is $1.0145 \mathrm{~Hz}$, which indicates that $\omega_{F}$ deviated from its natural frequency $1.1 \mathrm{~Hz}$ (dashed line) calculated from linear wave theory. According to effects of filling levels on natural frequency, for $D / L=0.35$, the offset is $-5 \%$ [39]. Fig. 6 also depicts the free surface profiles when structural response reaches the maximum value for $f_{e}=1.0 \mathrm{~Hz}, 1.1 \mathrm{~Hz}$ and $1.9 \mathrm{~Hz}$. The damper can absorb the energy transferred from the structural motion and release the energy through shear force to restrain the vibration conversely. On one hand, most of the energy acts on the structure in the form of shear force provided by viscous force and pressure variation. On the other hand, a portion of the energy is lost by internal fluid interaction through the creation of vorticity and formation of wave breaking. The wave profiles in Fig.6 show that, at the first resonance frequency, violent wave breaking due to sloshing occurred near the middle of tank, which means the fluid have to release energy through internal fluid interaction to dissipate energy to achieve balance result from the enormous vibrational energy input. In the other words, the energy efficiency reduced due to nonlinear motions of fluid, thus proper damper parameters should be adopted to improve damping capability of TLD.

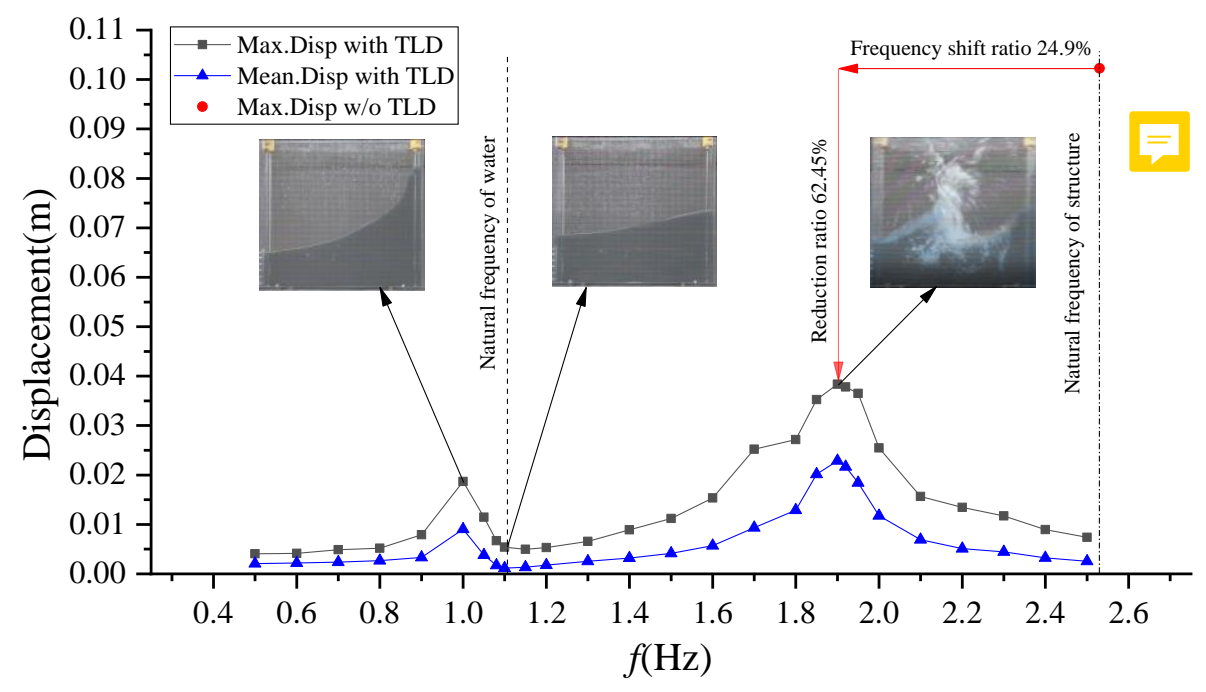

Fig. 6. Maximum and mean roof response curve of TLD-SSP coupling system by shaking table test. (dashed line and dash-dotted line represents the natural frequency of TLD and SSP respectively).

To further investigate certain parameters on the damper performance numerically, the recorded displacements of the roof plate and free surface elevations in the tank were utilized to validate the present numerical model. The external excitation frequencies selected were $1.6 \mathrm{~Hz}$ and $1.9 \mathrm{~Hz}$, and the corresponding frequency ratio was 0.84 and 1.0 respectively. The simulation results including roof plate displacements and sloshing wave elevations of the coupled system 
from the FVM/FEM solvers are compared with the experimental results in Fig. 7 and Fig. 8, showing a good agreement. Meanwhile, the sf at energy distribution of the structural response has been obtained by Fast Fourier Transforn. (FT) in Fig. 9 and compared to that from the experiments. The small discrepancy between the two results could be caused by the high frequency signal of the motion simulator. It is clear that the roof plate displacements tend to be stable at resonance frequency with a frequency ratio of 0.84 . This phenomenon is closely related to sloshing waves in tank, the hydrodynamic force acting on the walls is considered to be equivalent to a shear force in the opposite direction to the structure motion. In addition, at $T=3.9$ seconds, the wave height reaches its peak value as shown in Fig. 8, which is due to the fluid energy imbalance caused by the sudden excitation. The mechanism for an effective TLD is down to the process of absorbing and releasing energy, which take place simultaneously. As roof plate displacement increases gradually, the liquid in the container cannot release energy without the stable sloshing waves developed in time, so part of the energy is presented in the form of potential energy with an increased wave height.

The nonlinearity of fluid force is closely related to the coupled vibration. Comparisons of free surfaces in the tank between the experimental and numerical results are presented in Fig. 10 for the frequency ratios of 0.84 and 1.0. In the numerical results, the free surfaces (highlighted in green) are represented by the volume of fraction value of 0.5 . The results highlighted that the numerical model can accurately predict the evolution of free surface during violent sloshing, including large deformation of waves and local wave breaking phenomenon. It should be noted that the VOF method provides a smooth transition of phase volume $\alpha$ from 0 to 1 , and the thickness of the transition layer depends on the density of the grids. Therefore, the height of splashing zone of broken waves predicted numerically was lower than experimental results, as shown in Fig. 10(h) for $\mathrm{T}=5.9 \mathrm{~s}$.

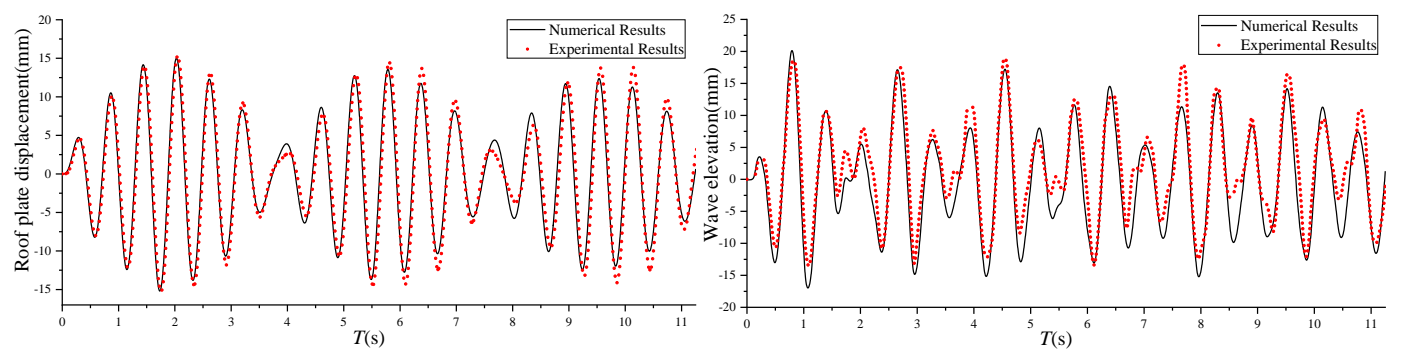

Fig. 7. Comparison of roof displacement and wave time histories when frequency ratio is 0.84 by experimental and numerical methods.
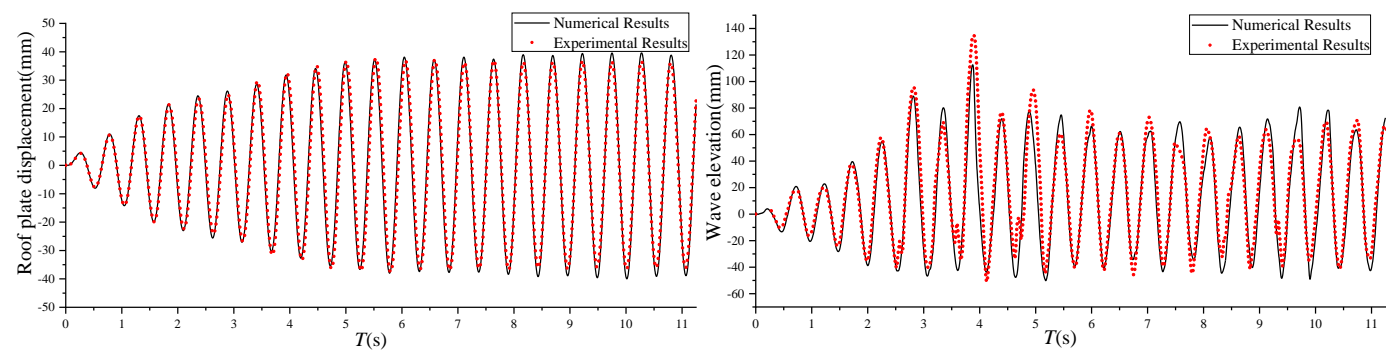

Fig. 8. Comparison of roof displacement and wave time histories under resonance by experimental and numerical methods. 

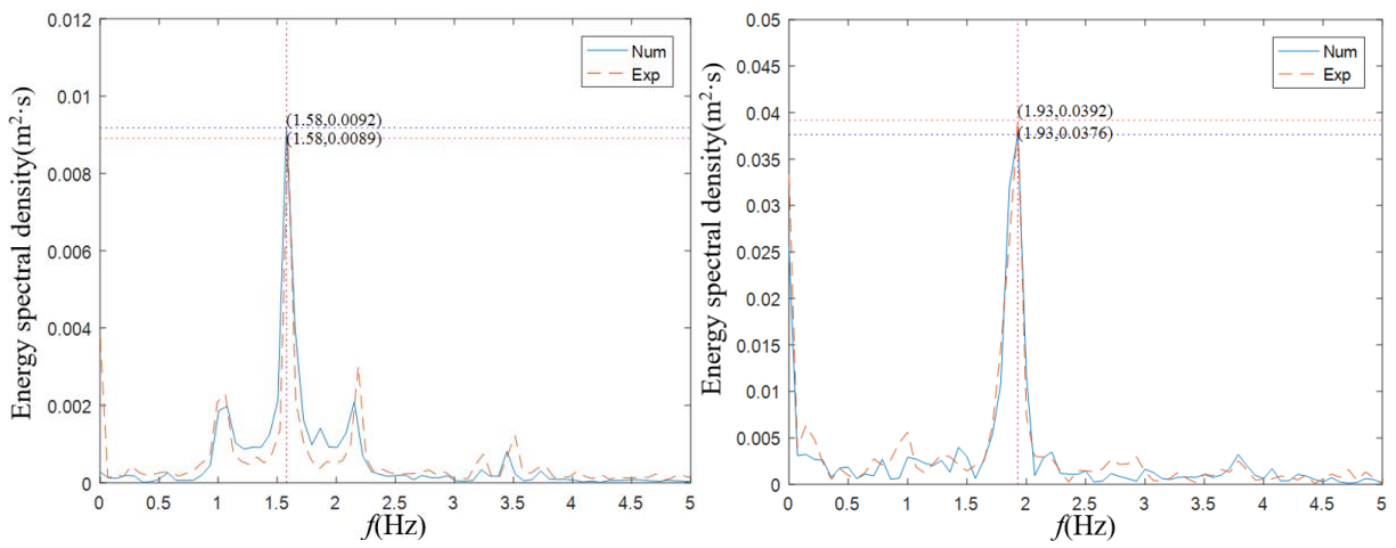

Fig. 9. Spectral analysis of top motion response when frequency ratio is 0.84 and 1.0.
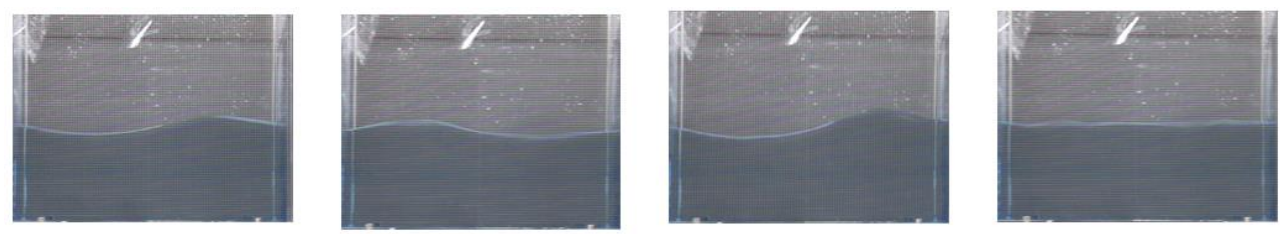

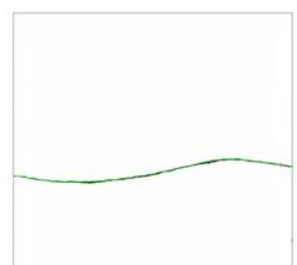

(a) $T=0.8 \mathrm{~s}$
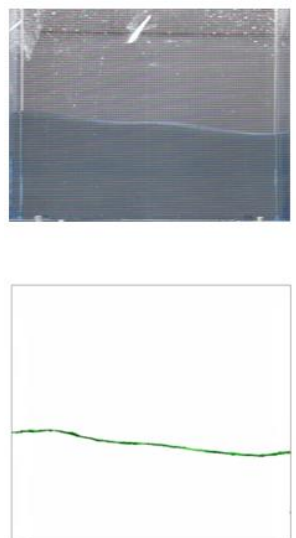

(e) $T=1.0 \mathrm{~s}$

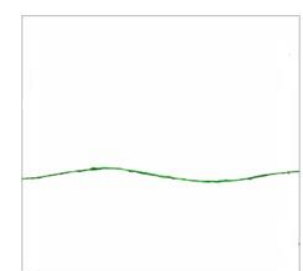

(b) $T=1.8 \mathrm{~s}$
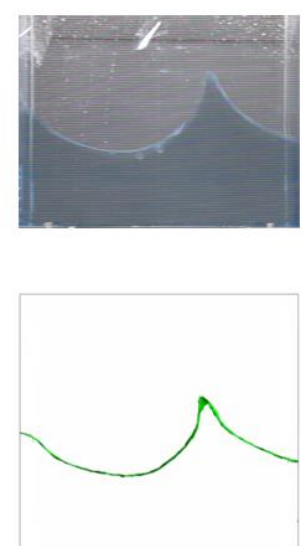

(f) $T=2.0 \mathrm{~s}$

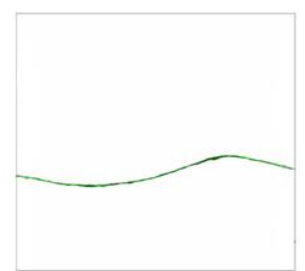

(c) $T=5.7 \mathrm{~s}$
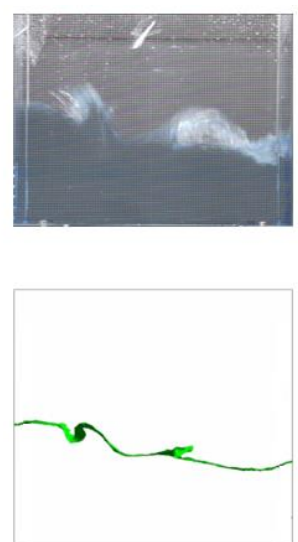

(g) $T=2.6 \mathrm{~s}$

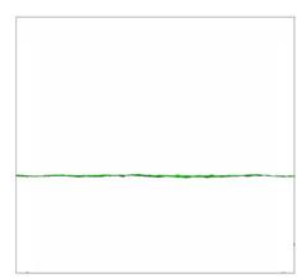

(d) $T=5.8 \mathrm{~s}$
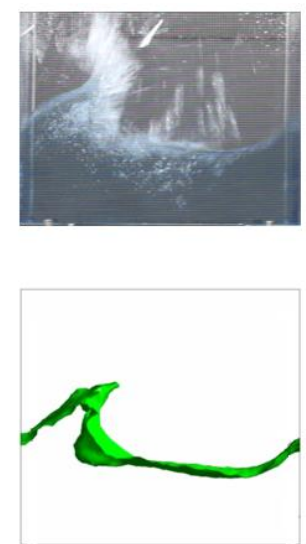

(h) $T=5.9 \mathrm{~s}$

Fig. 10. Comparisons of free surface in the tank by experimental and numerical method. ((a)-(d): frequency ratio $=0.84$, (e)-(h): frequency ratio=1.0).

In addition, to ensure the numerical results to be independent of the element size, five meshes of different sizes for the fluid and solid domains were used for grid convergence test. As shown in Table 2, the changes in the numerical results from the previous level of the meshes become small when the fluid and solid size was $0.004 \mathrm{~m}$ and $0.006 \mathrm{~m}$ respectively.

Table 2 Mesh dependence tests.

\begin{tabular}{|c|c|c|c|}
\hline $\begin{array}{c}\text { Grid size of } \\
\text { fluid } \\
\text { domain }(\mathrm{mm})\end{array}$ & $\begin{array}{c}\text { Grid size of } \\
\text { solid } \\
\text { domain }(\mathrm{mm})\end{array}$ & $\begin{array}{l}\text { The maximum horizontal } \\
\text { displacement of structure }(\mathrm{mm})\end{array}$ & $\begin{array}{c}\text { The maximum wave height of the } \\
\text { monitoring point }(\mathrm{mm})\end{array}$ \\
\hline 10 & 10 & $5.69 \%$ & $7.17 \%$ \\
\hline
\end{tabular}




\begin{tabular}{cccccc}
\hline 8 & 8 & 36.29 & $2.18 \%$ & 77.56 & $3.20 \%$ \\
6 & 8 & 36.88 & $0.59 \%$ & 79.43 & $0.86 \%$ \\
6 & 6 & 37.02 & $0.22 \%$ & 79.61 & $0.64 \%$ \\
4 & 6 & 37.10 & $/$ & 80.12 & $/$ \\
\hline
\end{tabular}

\section{Results and discussion}

As demonstrated in Section 4, the developed numerical model was a robust tool for simulating interactions between sloshing waves and structural vibration. In this section, damper parameters such as the mass ratio and frequency ratio are examined to evaluate the TLD damping performance. In the previous work [40], the mass ratio was recommended in the range of $1 \%-4 \%$. Therefore, five mass ratio values $(1 \%, 2 \%, 3 \%, 4 \%$ and $5 \%)$ and five frequency ratio values $(0.8$, $0.9,1.0,1.1$ and 1.2) with a total of 25 cases were adopted to investigate the damping performance and energy dissipation. For different frequency ratios, the width of the container was adjusted to keep the mass ratio constant. The mass ratio and frequency ratio are defined as

$$
\begin{aligned}
& \text { Mass ratio }=\frac{M_{F}}{M_{S}} \times 100 \% \\
& \text { Frequency ratio }=\frac{\omega_{L}}{\omega_{s}}
\end{aligned}
$$

where $M_{F} 、 M_{S} 、 \omega_{L}$ and $\omega_{S}$ are the mass and natural frequency of fluid and structure, respectively.

To minimize the effects of depth ratio $D / L$ on sloshing waves and the natural frequency, the $D / L$ was kept at $35 \%$ which is a medium depth ratio value. The dimensions of the TLD are presented in Table 3 for different frequency and mass ratios. Inevitably, the mass of tank will change with the different TLD dimensions, but this part of the mass is relatively small

Table 3 The dimensions of tanks with different mass ratios and frequency ratios.

\begin{tabular}{ccccccccc}
\hline \multirow{2}{*}{$\begin{array}{c}\text { Frequency } \\
\text { ratio }\end{array}$} & $L(\mathrm{~m})$ & $D(\mathrm{~m})$ & \multicolumn{7}{c}{$W(\mathrm{~m})$} & \\
\cline { 4 - 8 } & & & $1 \%$ & $2 \%$ & $3 \%$ & $4 \%$ & $5 \%$ \\
\hline 0.8 & 0.153 & 0.053 & 0.039 & 0.0778 & 0.117 & 0.156 & 0.195 & $35 \%$ \\
0.9 & 0.120 & 0.042 & 0.0627 & 0.1254 & 0.188 & 0.251 & 0.313 & $35 \%$ \\
1 & 0.098 & 0.034 & 0.0946 & 0.189 & 0.284 & 0.378 & 0.473 & $35 \%$ \\
1.1 & 0.081 & 0.0283 & 0.139 & 0.278 & 0.418 & 0.557 & 0.696 & $35 \%$ \\
1.2 & 0.068 & 0.0237 & 0.198 & 0.395 & 0.593 & 0.791 & 0.988 & $35 \%$ \\
\hline
\end{tabular}

\subsection{Effects of the mass and frequency ratios of TLD to SSP on structural vibration and} energy dissipation

It is desirable to use numerical methods because of the restricted frequency and load ranges of the six DOFs motion simulator. In addition, it is costly to construct a large number of different TLDs to obtain the desired damper parameters for the physical tests. The foundation of the SSP was subjected to harmonic resonance excitation, and the structural damping ratio was kept at $0.28 \%$ which is consistent with the experimental model. Due to the fluid-structure coupling procedure being iterated five times on the FSI boundary surfaces, for three-dimensional simulation, there is a 
big demand for computing power and internal memory. Therefore, all the numerical simulations were conducted for 15 seconds which covers about 40 motion response periods. For providing a fair comparison, the frequency and amplitude of the external excitation were kept constant at 2.53 $\mathrm{Hz}$ and $3 \mathrm{~mm}$, respectively.

Fig. 11 shows the comparison of time histories and spectral energy distribution of roof plate displacements between the coupled system and bare structure for different mass ratios. It can be seen that there will be no significance improvement on vibration reduction when the mass ratio is over $3 \%$, a positive value indicates that the system response is generally controlled while a negative reflects there is local increase attributes to frequency shift when mass ratio is $5 \%$. The small frequency shift was caused by the changed water mass, which has been observed by other researchers, when the mass ratio is increased [41]. Although the natural frequency of the liquid was consistent to the structure, the increased total mass has reduced the natural frequency of the coupled system.From the spectrum distributions, the occurrence of the secondary peak at the mass ratio of 5\% indicates that the system was mistuned and the damping performance had been negative affected.

The numerical results for maximum roof plate displacement reduction for different mass ratios and for different frequency ratios are shown in Fig. 12. As it can be seen, there is a notable effect on suppressing structural vibration when the mass ratios increase from $1 \%$ to $5 \%$, with the maximum reduction ratio increased from $31.83 \%$ to $79.47 \%$. As shown by the thick fold line, the optimal frequency ratio of vibration absorption is moving to 0.8 with the increase of the mass ratio. The frequency shift can be clearly observed and, in other words, the desired natural frequencies will change in response to different dimensions of damper. Therefore, in the design of TLD, the influence of damper mass on structural resonance frequency should be taken into account in order to improve the damper performance.

The Fig. 13 illustrates the dissipated energy by the dampers for the selected mass and frequency ratios. Considering as a whole, the structure will be affected by the external excitation and the hydrodynamic force in the tank. Therefore, the dissipated energy can be obtained by integrating the area of the hysteretic cycles developed in the hydrodynamic force versus container motion plane. In terms of energy, a mass ratio of $2 \%$ can maximize the energy dissipation ability of the sloshing absorber, and the optimal frequency ratio is kept at 1.0 for different mass ratios in the present study. The reason for this is that the dissipated energy is related to structural responses and hydrodynamic forces - although an increase of mass ratio can provide greater shear force, a larger total mass will reduce the amplitudes of the container. By increasing the mass ratio, phase difference deviated from180 degrees between shear force and top motion curves because of frequency shift. In other words, once the frequency shift occurs, the direction of horizontal motion may coincide to that of shear force during a period of vibration, which indicates the damping force may increase the accelerated of the structural motion.

From this study, although a TLD with a mass ratio of 5\% can still suppress the vibration of structure effectively, considering the frequency shift and energy dissipation, a mass ratio of $2 \%$ is recommended to maximize the energy dissipation characteristics of damper and avoid the negative effects of mistuning on damper performance. 

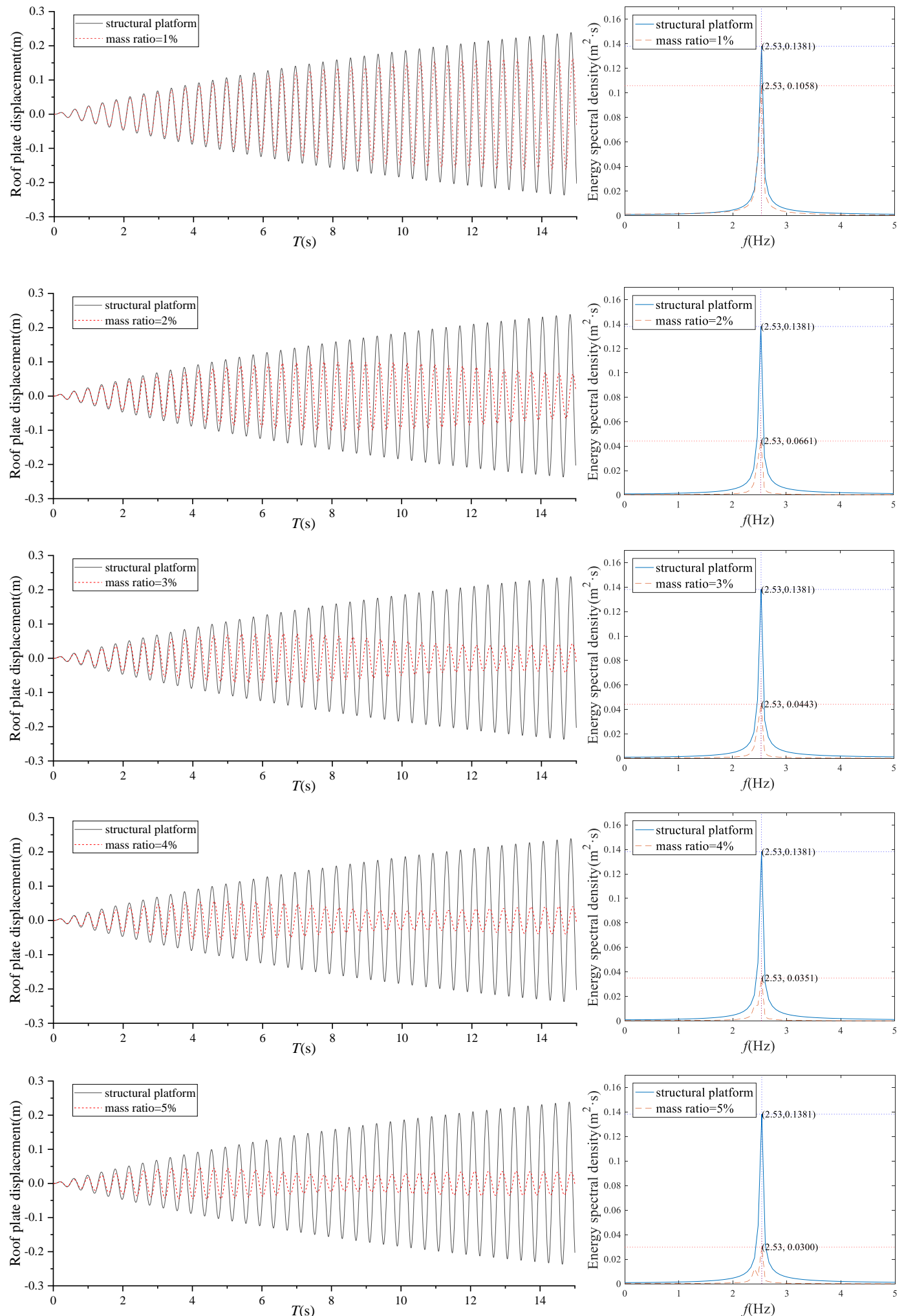

Fig. 11. Time histories and spectral energy distribution comparisons of roof plate displacements between coupled system and bare structure. 


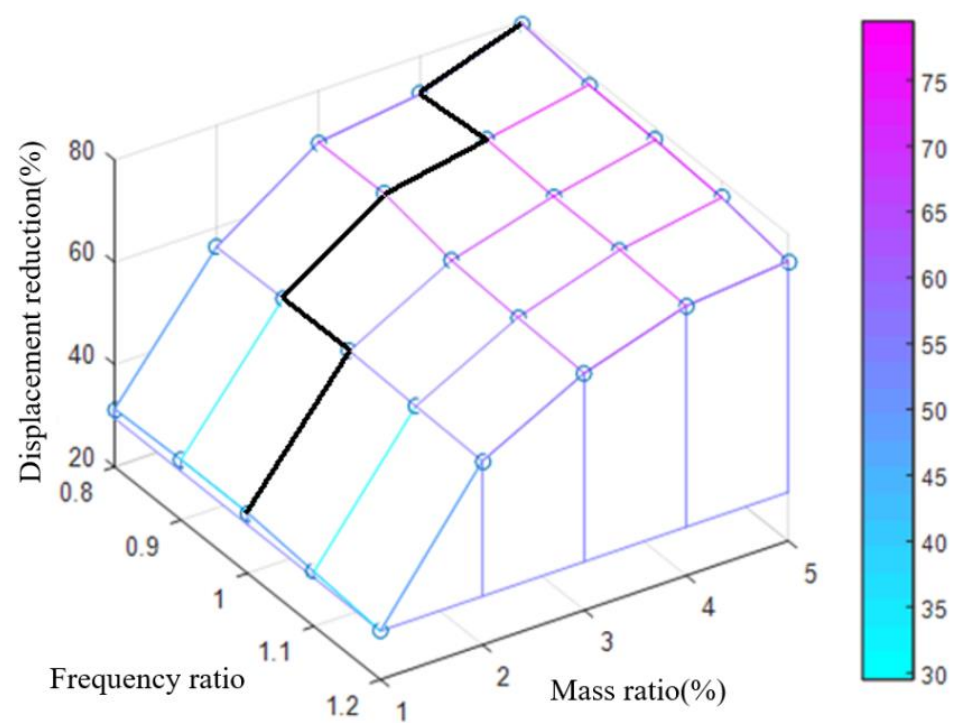

Fig. 12. Numerical results for maximum amplitude reduction for different mass ratios and frequency ratios. (Thick fold line represents the value of maximum displacement reduction under different mass ratios)

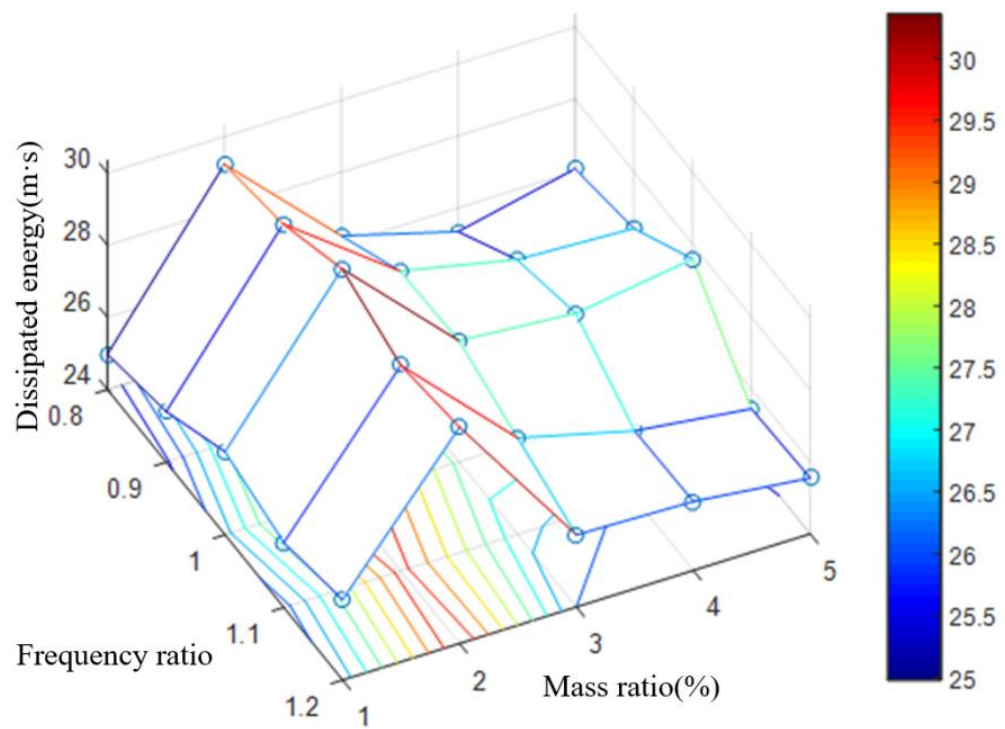

Fig. 13. Dissipation energy obtained numerically for different mass and frequency ratios.

\subsection{Numerical prediction of sloshing waves}

Wavelet transform has been successfully applied to analyze the hydroelastic effects of sloshing [42] and the nonlinear damping mechanism of tuned liquid column dampers [43]. In order to analyze the nonlinear interactions of the TLD-SSP system, wavelet transform was adopted to present the frequency components of free surface elevation.

Numerical results for time history and wavelet transform of wave elevations cloase to tank wall under resonance excitation are presented in Fig. 14. As is-shown that the maximum wave elevations always appear at the third peak, and the amplitudes reduces with the increase of mass. As the input amplitude of the external excitation was fixed, it clearly indicates that the fluid velocity in the tank decreases for each case. Besides, it can be seen from the wave elevations betwwen $T=5$ and $T=15$ second $_{2}$ the sloshing waves became mistuned when the mass ratio is increased. As the wave height decreases, the damping force provided by the high mass ratio on the 
same area will reduce. From the variation in the frequency components of the sloshing waves in time domain with different mass ratios, it can be concluded that spectral peak frequency is equal to the external excitation frequency since the TLD is tuned to the structure. The fluid in the tank absorbs energy through structural motion and at the same time release energy by shear force to control vibration. In the first two seconds of the system response, the sudden excitation has always caused the violent motion of the free surface because the energy obtained by the fluid was greater than the energy released. With the steady formation of sloshing waves, the energy in the fluid was gradually balanced. It is noted that, when the mass ratio is $4 \%$ and $5 \%$, the frequency components of sloshing waves exhibited nonlinear characteristics with the evolution of sloshing process, wavelet ridge can be observed in low frequency domain. In other words, frequent intermittent loads may cause the imbalance of TLD energy absorption and release, which enhance the nonlinear-coupled vibration, based on which TLDs with mass ratio of 1\%-3\% are recommended for enhancing the SSP stability.

In Fig. 15 the spectral peak values of sloshing waves with different mass and frequency ratios by FFT are given, where the spectral peak frequency is 2.53 which are equal to the first resonance frequency of bare structure. As seen, when mass ratio is $1 \%$, the maximum spectral peak occurred at the $\omega_{L} / \omega_{S}=1.0$, which indicates the higher sloshing wave can be generated if TLD is tuned to the structural frequency, resulting in a better damping performance. However, the maximum of spectral peak gradually shifted to low frequency ratios when the mass ratio is increased. The reason for this is that the added mass of tank leads to the shift of the natural frequency of the TLD-SSP system. It weakens the shear force provided by pressure on the walls which is in correlation with wave height in the tank. The changes of spectral energy can also reflect the trend of the optimal vibration reduction fold line in Fig.13 as it moves to the low frequency ratio. Resonance of liquid in container will maximize energy absorbing ability and ultimately determine the vibration reduction effect of the damper. So the mass of TLD should be reduced as much as possible when designing slender TLD and adding frequency modulation baffles, in order to improve its ability to restrain the vibration of structures.
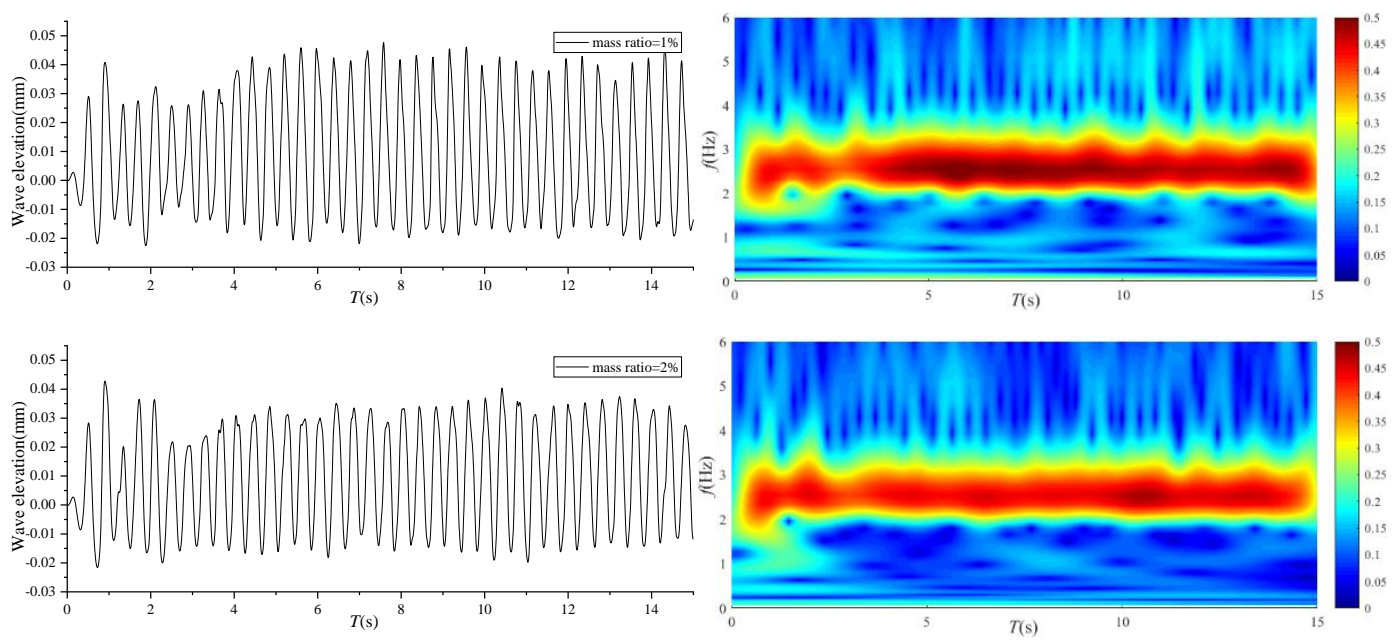

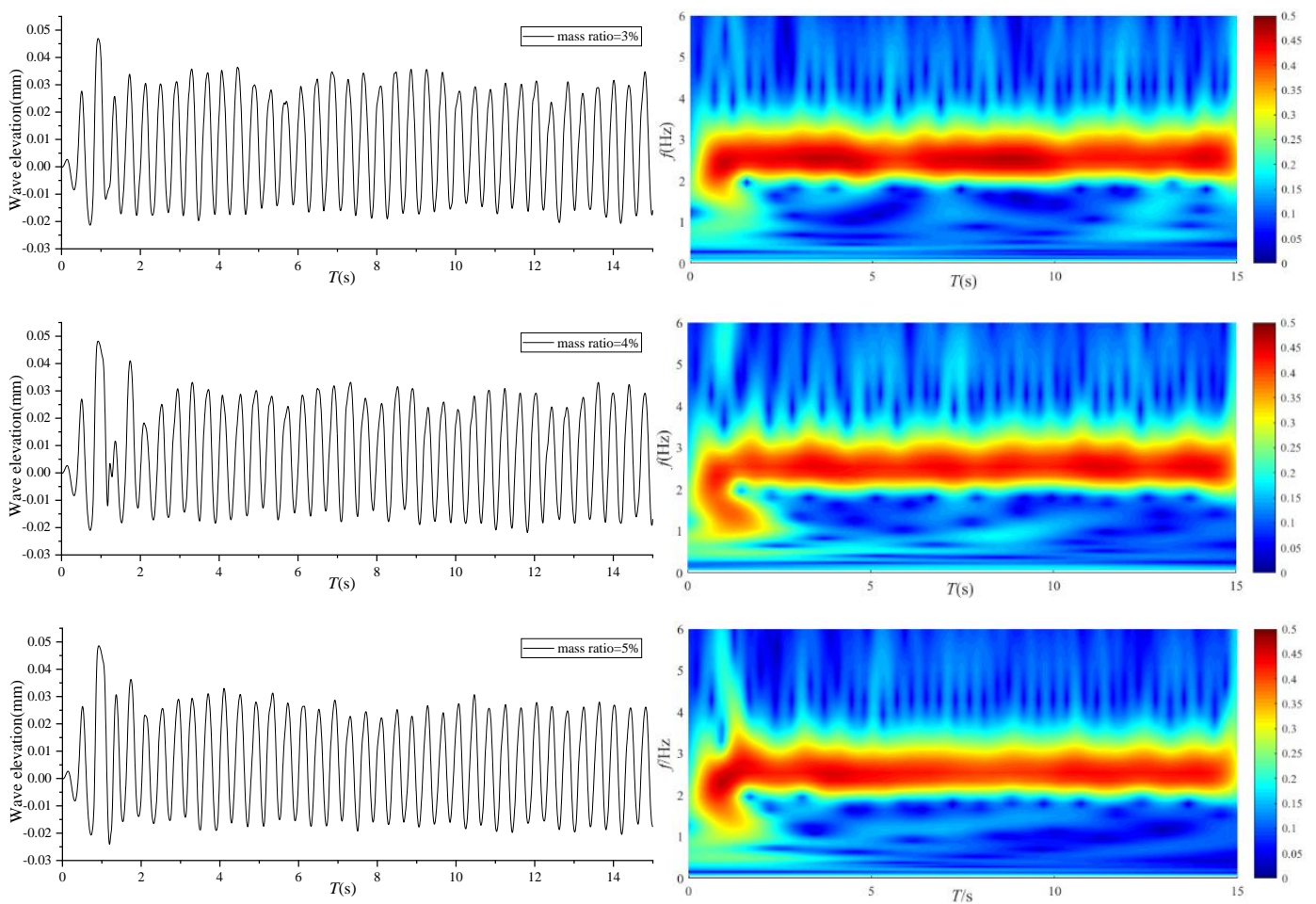

Fig. 14. Numerical results for time history and wavelet transform of free surface elevations under resonance excitation. (Frequency ratio $=1.0$, mass ratio $=1 \%, 2 \%, 3 \%, 4 \%$ and $5 \%$ ).

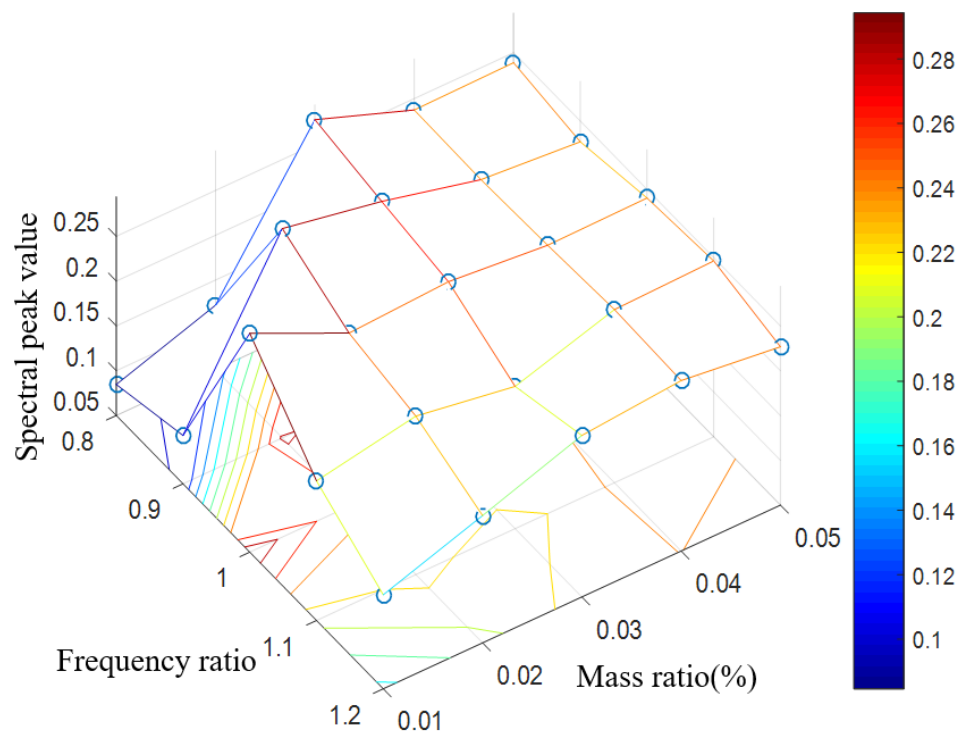

Fig. 15. Numerical results for the spectral peak values of sloshing waves with different mass ratios and frequency ratios.

\section{Conclusions}

The performance of Tuned Liquid Damper (TLD) in suppressing the elastic supporting structural platform (SSP) responses under various horizontal excitations was investigated. A steel SSP structure with a total height of $1.01 \mathrm{~m}$ was constructed in order to validate a two-way coupled model for the simulation of nonlinear vibrations of the coupled system. The energy transmission mechanism in the damper is analyzed in this study and the effects of the mass and frequency ratios on TLD performance including structural responses and sloshing waves were evaluated through 
numerical experiments. Special attention has been paid to energy dissipation with different mass and frequency ratios, which has contributes, to improve damping performance of TLD. Main conclusions are summarized as follows:

(1) Structural vibration can be substantially reduced when TLD is installed on the roof plate (by $62.45 \%$ ), and natural frequency of the structure is reduced from $2.53 \mathrm{~Hz}$ to $1.90 \mathrm{~Hz}$. However, if the TLD is mistuned to the first resonance frequency, it will have a negative impact on the damper performance as the external excitation causes liquid resonance in the tank. Roof plate response is violent under the first resonance frequency and energy of the liquid will be dissipated through formation of vortices and wave breaking.

(2) Through comparing with the experimental data obtained in the laboratory, it is shown that the two-way coupling model is a reliable tool for simulating the interactions between sloshing waves and structural vibration. It can not only predict the structural deformation accurately, but also the nonlinear violent free surface flow motion (sloshing).

(3) It is observed that, by increasing the mass ratio from $1 \%$ to $5 \%$, the optimal frequency ratio of roof plate displacement moved from 1.0 to 0.8 . Although the damper with higher mass ratio could further suppress the structural vibration, by considering the frequency shift and energy dissipation, a $2 \%$ mass ratio is recommended to maximize the energy dissipation capacity of damper and avoid the negative effects of mistuning.

(4) The damper absorbs energy through structural response, and at the same time dissipates energy by shear force to control vibration. The sudden excitation breaks the balance of energy absorption and production in fluids resulting in larger wave height, which will impact on the tank and in turn reduce structural stability, especially for a mass ratio between 3\%-5\%. Therefore, in addition to moderately increasing the frequency ratio according to the mass of TLD $M_{F}$, the optimal mass for the TLD should be less than $3 \%$ of the structural mass.

\section{Acknowledgement}

This work is supported by the National Natural Science Foundation of China (No. 51679079), the National Science Found for Distinguished Young Scholars (No. 51425901), the Fundamental Research Funds for the Central Universities (No. 2018B12814), and the Program for Excellent Innovative Talents of Hohai University.

Conflict of Interest: The authors declare that they have no conflict of interest.

\section{Reference}

1. El-Sayad, M.A., Hanna, S.N., Ibrahim, R.A.: Parametric excitation of nonlinear elastic systems involving hydrodynamic sloshing impact. Nonlinear Dyn. 18(1), 25-50 (1999)

2. Ikeda, T.: Nonlinear parametric vibrations of an elastic structure with a rectangular liquid tank. Nonlinear Dyn. 33(1), 43-70 (2003)

3. Fediw, A.A., Isyumov, N., Vickery, B.J.: Performance of a tuned sloshing water damper. J. Wind Eng. Ind. Aerodyn. 57(2-3), 237-247 (1995)

4. Jin, Q., Li. X., Sun, N., Zhou. J., Guan, J.: Experimental and numerical study on tuned liquid dampers for controlling earthquake response of jacket offshore platform. Mar. Struct. 20(4), 238-254 (2007)

5. Fu, L., Guo, T., Li, G.: Investigation on damping performance of new type oscillator-liquid combined damper. 
Int. J. Mech. Sci. 135, 53-62 (2018)

6. Pabarja, A., Vafaei, M., Alih, S.C., Yatim, M.Y.M., Osman, S.A.: Experimental study on the efficiency of tuned liquid dampers for vibration mitigation of a vertically irregular structure. Mech. Syst. Signal Proc. 114, 84-105 (2019)

7. Mousavi, S.A., Zahrai, S.M., Bargi, K.: Optimum geometry of tuned liquid column-gas damper for control of offshore jacket platform vibrations under seismic excitation. Earthq. Eng. Eng. Vib. 11(4), 579-592 (2012)

8. Zhang, C., Zhang, Q.Y., Zheng, J.H., Demirbilek, Z.: Parameterization of nearshore wave front slope. Coast. Eng. 127, 80-87 (2017)

9. Dong, G.H., Ma, Y.X., Perlin, M., Ma, X.Z., Yu, B., Xu, J.W.: Experimental study of wave-wave nonlinear interactions using the wavelet-based bicoherence. Coast. Eng. 55(9), 741-752 (2008)

10. Cavalagli, N., Biscarini, C., Facci, A.L., Ubertini, F., Ubertini, S.: Experimental and numerical analysis of energy dissipation in a sloshing absorber. J. Fluids Struct. 68, 466-481 (2017)

11. Xue, M.A., Lin, P.Z.: Numerical study of ring baffle effects on reducing violent liquid sloshing. Comput. Fluids 52, 116-129 (2011)

12. Xue, M.A., Zheng, J.H., Lin, P.Z.: Numerical simulation of sloshing phenomena in cubic tank with multiple baffles. J. Appl. Math. 245702 1-21 (2012)

13. Xue, M.A., Lin, P.Z., Zheng, J.H., Ma, Y.X., Yuan, X.L., Nguyen, V.T.: Effects of perforated baffle on reducing sloshing in rectangular tank: experimental and numerical study. China Ocean Eng. 27(5), 615-628 (2013)

14. Xue, M.A., Zheng, J.H., Lin, P.Z., Yuan, X.L.: Experimental study on vertical baffles of different configurations in suppressing sloshing pressure. Ocean Eng. 136, 178-189 (2017)

15. Tait, M.J., El Damatty A.A., Isyumov, N., Isyumov, N., Siddique, M.R.: Numerical flow models to simulate tuned liquid dampers (TLD) with slat screens. J. Fluids Struct. 20(8), 1007-1023 (2005)

16. Xu, X., Guo, T., Li, G.J., Sun, G.P., Shang, B.B., Guan, Z.C.: A combined system of tuned immersion mass and sloshing liquid for vibration suppression: Optimization and characterization. J. Fluids Struct. 76, 396-410 (2018)

17. Ha, M., Cheong, C.: Pitch motion mitigation of spar-type floating substructure for offshore wind turbine using multilayer tuned liquid damper. Ocean Eng. 116, 157-164 (2016)

18. Ong, P.P., Adnan, A., Kwok, K.C.S., Ma, C.K., Tiong, P.L.Y., Behbahani, H.P.: Dynamic simulation of unrestrained interlocking Tuned Liquid Damper blocks. Constr. Build. Mater. 144, 586-597 (2017)

19. Rai, N.K., Reddy, G.R., Venkatraj, V.: Tuned Sloshing Water Dampers as Displacement Response Reduction Device: Experimental Verification. Int. J. Struct. Stab. Dyn. 17(2), 1750026 (2017)

20. Xue, S.D., Ko, J.M., Xu, Y.L.: Tuned liquid column damper for suppressing pitching motion of structures. Eng. Struct. 22(11), 1538-1551 (2000)

21. Wu, J.C., Shih, M.H., Lin, Y.Y., Shen, Y.C.: Design guidelines for tuned liquid column damper for structures responding to wind. Eng. Struct. 27(13), 1893-1905 (2005)

22. Lee, H.H., Wong, S.H., Lee, R.S.: Response mitigation on the offshore floating platform system with tuned liquid column damper. Ocean Eng. 33(8-9), 1118-1142 (2006)

23. Lee, S.K., Park, E.C., Min, K.W., Lee, S.H., Chung, L., Park, J.H.: Real-time hybrid shaking table method for the performance evaluation of a tuned liquid damper controlling seismic response of building structures. J. Sound Vibr. 302(3), 596-612 (2007)

24. Altunisik, A.C., Yetisken, A., Kahya, V.: Experimental study on control performance of tuned liquid column dampers considering different excitation directions. Mech. Syst. Signal Proc. 102, 59-71 (2018)

25. You, K.P., Kim, Y.M., Yang, C.M., Hong, D.P.: Increasing damping ratios in a tuned liquid damper using 
damping bars. Asian Pacific Conference for Fracture and Strength 1-4, 353-358 (2007)

26. Ruiz, R.O., Lopez-Garcia, D., Taflanidis, A.A.: Modeling and experimental validation of a new type of tuned liquid damper. Acta Mech. 227(11), 1-20 (2016)

27. Hsu, M.C., Bazilevs, Y.: Fluid-structure interaction modeling of wind turbines: simulating the full machine. Comput. Mech. 50(6), 821-833 (2012)

28. Nikoo, H.M., Bi, K.M., Hao, H.: Effectiveness of using pipe-in-pipe (PIP) concept to reduce vortex-induced vibrations (VIV): Three-dimensional two-way FSI analysis. Ocean Eng. 148, 263-276 (2018)

29. Sodja, J., De Breuker, R., Nozak, D., Drazumeric, R., Marzocca, P.: Assessment of low-fidelity fluid-structure interaction model for flexible propeller blades. Aerosp. Sci. Technol. 78, 71-88 (2014)

30. Malekghasemi, H., Ashasi-Sorkhabi, A., Ghaemmaghami, A.R., Mercan, O.: Experimental and numerical investigations of the dynamic interaction of tuned liquid damper-structure systems. J. Vib. Control 21(14), 2707-2720 (2013)

31. Ashasi-Sorkhabi, A., Malekghasemi, H., Ghaemmaghami, A., Mercan, O.: Experimental investigations of tuned liquid damper-structure interactions in resonance considering multiple parameters. J. Sound Vibr. 388 , 141-153 (2017)

32. Kwon, J., Monaghan, J.J.: A novel SPH method for sedimentation in a turbulent fluid. J. Comput. Phys. 300, 520-532 (2015)

33. Anghileri, M., Castelletti, L.M.L., Francesconi, E., Milanese, A., Pittofrati, M.: Rigid body water impact-experimental tests and numerical simulations using the SPH method. Int. J. Impact Eng. 38(4), 141-151 (2011)

34. Kim, K.S., Kim, M.H., Park, J.C.: Development of moving particle simulation method for multi-liquid-layer sloshing. Math. Probl. Eng. 1,282-290 (2014)

35. La Rocca, M., Sciortino, G., Adduce, C., Boniforti, M.A.: Experimental and theoretical investigation on the sloshing of a two-liquid system with free surface. Phys. Fluids 17(6), 211-226 (2005)

36. Smagorinsky, J.: General circulation experiments with the primitive equations. Mon. Weather Rev. 91, 99-164 (1963)

37. Lilly, D.K.: A proposed modification of the Germano subgrid-scale closure method. Phys. Fluids A 4, 633-635. (1992)

38. Germano, M., Piomelli, U., Moin, P., William, H.: A dynamic subgrid-scale eddy viscosity model. Phys. Fluids A 3, 1760-1765 (1998)

39. Chen, Y.C., Xue, M.A.: Numerical simulation of liquid sloshing with different filling levels using OpenFOAM and experimental validation. Water 10(12) 1752 (2018)

40. Banerji, P., Murudi, M., Shah, A.H., Popplewell, N.: Tuned liquid dampers for controlling earthquake response of structures. Earthq. Eng. Struct. Dyn. 29(5), 587-602 (2000)

41. Pabarja, A., Vafaei, M., Alih, S.C., Yatim, M.Y.M., Osman, S.A.: Experimental study on the efficiency of tuned liquid dampers for vibration mitigation of a vertically irregular structure. Mech. Syst. Signal Proc. 114, 84-105 (2019)

42. Jiang, M.R., Zhong, W.J., Yu, J.X., Liu, P.L., Yin, H.J., Wang, S.D., Ma, Y.X.: Experimental Study on sloshing characteristics in the elastic tank based on Morlet Wavelet transform. China Ocean Eng. 32(4), 400-412 (2018)

43. Dziedziech, K., Staszewski, W.J., Ghosh, A., Basu, B., UhI, T.: Characterisation of instantaneous dynamic parameters in vibration analysis of tuned liquid column dampers. Nonlinear Dyn. 90(1), 717-731 (2017) 